\section{Fruit Quality of Stored, Fresh Red Raspberries After a Delay in Precooling}

\author{
JoAnn Robbins ${ }^{1}$ and \\ Patrick P. Moore ${ }^{2}$
}

Additional index words. Rubus idaeus, $\mathrm{L}^{*}, \mathrm{a}^{*}, \mathrm{~b}^{*}$, fruit color, fruit strength, weight loss

Summary. The effects of delayed precooling on fresh red raspberry fruit during storage was determined. Precooling was delayed for 0.5 to 12 hours, followed by cold storage for 8 days, with subsequent storage at 20C for 24 hours. Weight loss was greater with increasing delays of precooling. Fruit that lost more weight during the delay period lost less during the subsequent $\mathrm{S}$-day storage at $0 \mathrm{C}$. The exception was fruit held for 12 hours before precooling. Weight loss during the final 24 hours at 20C showed no pattern. Cumulative weight loss at the end of the storage treatments was similar regardless of delay of precooling. Fruit strength was reduced by any delay of precooling. The effect of delayed precooling on color was not consistent in the 2 years using different cultivars. The results indicate that fruit should be precooled as quickly as possible after harvest for long-distance fresh marketing.

$\mathrm{R}$ aspberry (Rubus idaeus L.) fruit is highly perishable. To maintain good fruit quality, storage at 0.5 to $0 \mathrm{C}$ with $90 \%$ to $95 \% \mathrm{RH}$ has been recommended (Salunkhe and Desai, 1984). Precooling (prompt removal of the field heat to the storage or transport temperature) is recommended (Smith, 1958; Tomalin et al., 1972). Although there are published recommendations for storage and precooling of raspberries, there are no quanti-

Washington State University Puyallup Research and Extension Center, Puyallup, WA 98371-4998

${ }^{1}$ Horticulture Research Specialist. Current address: Univ. of Idaho Extension System, Rhine County, Box 216, Hailey, ID 83333.

${ }^{2}$ Assistant Horticulturist tative studies providing information on the effects of delayed precooling on raspberry fruit quality. In strawberries, delayed precooling resulted in more decay (Kenny 1975; Smith, 1958), in dark fruit (Smith, 1958), and significantly less marketable fruit in some cultivars (Ingle, 1970). Growers desiring top-quality fruit for long-distance fresh marketing often lack facilities close to their fields to accomplish prompt precooling. We studied the effects ofdelayed precooling on weight loss, strength, and fruit color of fresh red raspberries during storage.

\section{Materials and methods}

Studies in 1989. Fruit was harvested on 10 July 1989 at the red-ripe stage (Sjulin and Robbins, 1987) from four hill plots replicated three times of Chilcotin, Chilliwack, Meeker, and Willamette red raspberry growing at the Washington State Univ. Puyallup Research and Extension Center. Plants were sprayed weekly with Captan 50WP (2.4 g liter $^{-1}$ ) beginning in mid-June for control of postharvest rot due to Botrytis cinerea Pers. ex. Fr.

Ten fruit from each cultivar for each cooling-storage treatment combination was harvested into unwaxed, ventilated fiberboard containers $(10 \mathrm{x}$ $10 \times 3.4 \mathrm{~cm}$ high) with three replications (cups) per treatment. Field temperature during harvest ranged from 15.5 to $17 \mathrm{C}$, with a $\mathrm{RH}$ of $\approx 78 \%$.

Treatments consisted of delaying precooling for 0.5 (the time taken to harvest samples and transport them to the precooling tower), 2, 4, 8 , or $12 \mathrm{~h}$. During the delay period, fruit was held in a growth chamber at $20 \mathrm{C}$ and $62 \%$ RH. For precooling, samples were placed into a $0.5 \times 0.4 \times 1.8-\mathrm{m}$ plywood cooling tower in a cooler at $0 \mathrm{C}$, $90 \% \mathrm{RH}$. Air was forced through the tower for $4 \mathrm{~h}$ with a fan rated at 0.14 $\mathrm{rn}^{3} \mathrm{~s}^{1}$ at $100 \mathrm{~Pa}$ of static pressure. Temperature of the fruit was monitored with an electronic data logger (Omnidata, datapod, Logan, Utah) with the thermistor tip inserted in the receptacle cavity of a fruit. Fruit temperature dropped from $17 \mathrm{C}$ (in $0.5-\mathrm{h}$ delay sample) or $19.5 \mathrm{C}$ (in samples delayed at 20C) to $0 \mathrm{C}$ in $20 \mathrm{~min}$. After precooling, all treatments were held at 0C and 90\% RH for $192 \mathrm{~h}$ (8 days). They then were stored at 20C and 62\% $\mathrm{RH}$ for $24 \mathrm{~h}$ before evaluation, where temperature of the fruit changed from $0 \mathrm{C}$ to $19 \mathrm{C}$ in $4 \mathrm{~h}$. 
Fruit weight of the total sample $( \pm 0.1 \mathrm{~g})$ was recorded after harvest, after the delay period, after cold storage for 8 days, and after the subsequent $24 \mathrm{~h}$ at $20 \mathrm{C}$.

Fruit strength, as measured by the force to close the opening of the fruit (compression), was recorded on the 10 fruit from each replication (Robbins and Sjulin, 1986) after the final weighing.

Color was measured on the 10 fruit from each replication after the fruit strength measurements using a tristimulus color analyzer (Chroma Meter, Model CR-200b, Minolta Corp., Ramsey, N.J.) equipped with a measuring head with an 8-mm-diameter measuring area. The analyzer was calibrated to a standard white reflective plate and used CIE (Commission Internationate d 1 Eclairage) Illuminant C. Measurements were recorded in $L^{*}, a^{*}, b^{*}$ CIE (1976) coordinates. The $L^{*}$ scale ranges from no reflection $\left(\mathrm{L}^{*}=0\right.$, black) to perfect diffuse reflection $\left(L^{*}=100\right.$, white), the $a^{*}$ scale ranges from negative values for green to positive values for red, and the $b^{*}$ scale ranges from negative values for blue to positive values for yellow. Any presence of mold was noted.

Studies in 1990. Fruit was harvested on 18 and 20 July 1990 at the red-ripe stage from Centennial plants in a commercial planting. Harvest and storage methods were as in 1989, except field conditions were 19.5 to $21 \mathrm{C}$ with $\approx 68 \% \mathrm{RH}$ on both days and the delay and final $24 \mathrm{~h}$ of storage were at 20C with $71 \%$ RH.

For the 18 July harvest, fruit strength and weight loss were measured on five replications of two precooling delay treatments: $0.5-\mathrm{h}$ delay or $8-\mathrm{h}$ delay period. Measurements on 10 fruit were made either immediately after harvest, after the delay period, after $4 \mathrm{~h}$ of precooling at $0 \mathrm{C}$, after cold storage for 8 days, or after the subsequent $24 \mathrm{~h}$ at $20 \mathrm{C}$.

For the 20 July harvest, color was measured on three replications of 10 fruit precooled for $0.5 \mathrm{~h}$ after a 0.5., $2-, 4-, 8-$, or $12-\mathrm{h}$ delay at $20 \mathrm{C}$ stored at $0 \mathrm{C}$ for either $0,2,4,6$, or 8 days and then stored at $20 \mathrm{C}$ for $24 \mathrm{~h}$. Methods ofmeasurement were identical to those used in 1989.

\section{Results}

No mold was noted at any time on any of the fruit.

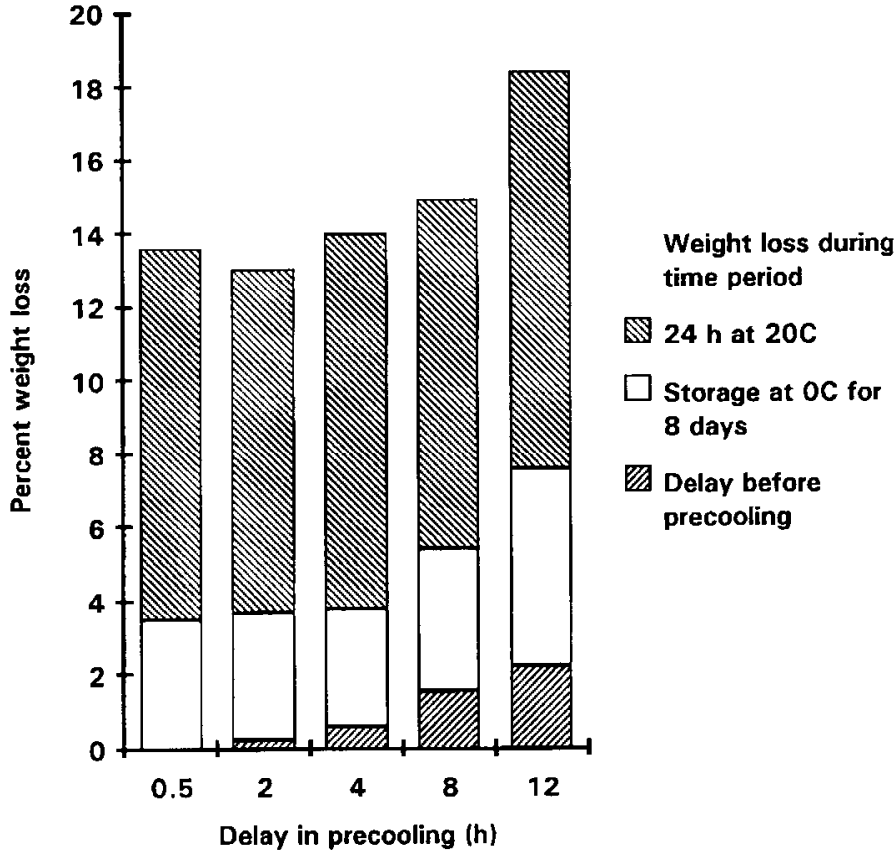

Fig. 1. The effect of delay before precooling on percentage of weight loss of four cultivars of red raspberry fruit during storage in 1989.

Weight loss. In 1989, weight loss during the delay increased linearly with increasing delay for all cultivars (Fig. 1, $P=0.01)$. This was a result of more hours at the higher temperature and in a greater percentage of weight loss per hour with increasing delay $(0.12 \%$, $0.15 \%, 0.19 \%, 0.19 \%$ /hfor $2,4,8$, and $12 \mathrm{~h}$ of delay, respectively). This differs from the results of Robinson et al. (1975), who reported weight loss was more rapid immediately after harvest, with the rate falling to a fairly steady value for fruit stored at a constant temperature.

During the time the fruit was in cold storage (excluding forced-air precooling period), there was a quadratic effect of delayed precooling on the weight loss $(P=0.01)$. At the end of the delay, precooling, and $8 \mathrm{~h}$ of storage, weight loss showed significant linear $(\mathrm{P}=0.05)$ and quadratic $(\mathrm{P}=$ $0.01)$ effects of delayed precooling (Fig. 1). With increasing delay up through $8 \mathrm{~h}$, weight loss during precooling decreased during the 8-day storage period. This might be due to dehydration during the delay of precooling period. Fruit not cooled for 12 $\mathrm{h}$ lost as much weight during the 8-day storage period as that delayed 0.5 to 4 $h$, possibly due to structural or metabolic changes that occurred during the long delay period at 20C. There were significant differences among cultivars, with Chilliwack losing more weight than the other cultivars during the 8day storage period (data not shown).

During the $24 \mathrm{~h}$ at 20C, there were significant effects of delayed precooling on weight change, but this was not related to cultivar or previous treatment and no pattern was evident (Fig. 1 ). Weight loss in the final $24 \mathrm{~h}$ occurred at a higher rate than during the delay before precooling $(0.26 \% / \mathrm{h})$, even though the fruit was stored under identical conditions.

The cumulative weight loss was affected significantly by delayed precooling, but showed no consistent pattern related to delay before precooling (Fig. 1). This might be due to the influence of the large amount of weight lost during the final $24 \mathrm{~h}$ at 20C. There were significant differ-

Table 1. Effect of delay in precooling on percent weight loss during storage of Centennial red raspberry, 1990.

\begin{tabular}{lrr} 
& \multicolumn{2}{c}{ Delay before precooling $(\mathrm{h})$} \\
\cline { 2 - 3 } From harvest to & \multicolumn{1}{c}{$\mathbf{0 . 5}$} & \multicolumn{1}{c}{ Cumulative weight loss (\%) } \\
& $0 \mathrm{c}^{z}$ & $0 \mathrm{~d}$ \\
After 0.5-h delay & - & $2.44 \mathrm{c}$ \\
After 8-h delay & $0.41 \mathrm{c}$ & $2.61 \mathrm{c}$ \\
After 4-h delay & & \\
After 8 days stor- & & \\
age at 0C & $4.17 \mathrm{~b}$ & $6.14 \mathrm{~b}$ \\
After 24 h at 20C & $9.17 \mathrm{a}$ & $10.82 \mathrm{a}$
\end{tabular}

${ }^{z}$ Mean separation within columns by Duncan s multiple range test, $P=0.05$. Mean separation done on aEn-transformed data. 
ences among cultivars, with Chilliwack losing more weight than the other cultivars by the end of the storage treatments (data not shown).

In 1990, weight loss in Centennial was similar to the cultivars studied in 1989 tests (Table 1). However, in 1990, the weight losses during precooling were separated from those of storage. There was relatively little weight loss during the forced-air precooling (Table 1). At the end of the storage at $0 \mathrm{C}$ and $24 \mathrm{~h}$ at $20 \mathrm{C}$, the cumulative weight losses were similar regardless of delay before precooling, and similar to other cultivars in 1989. Samples with a large initial weight loss during the delay before precooling had subsequent slower rates of weight loss.

Fruit strength. In 1989, fruit strength, as measured by compression after the final $24 \mathrm{~h}$ at $20 \mathrm{C}$ showed a linear decrease with each increase in delay before precooling (Fig. 2; $P=$ $0.01)$. The greatest difference in fruit strength after delay was between the 0.5-h delay and the 2-h delay, indicating that fruit strength was lost rapidly. Cultivars differed in overall firmness, but all showed similar changes (data not shown). In 1990, when fruit strength was measured after each storage step, the greatest change in the 8-h delayed fruit occurred during the delay period prior to precooling (Table 2). An S-h delay resulted in fruit with

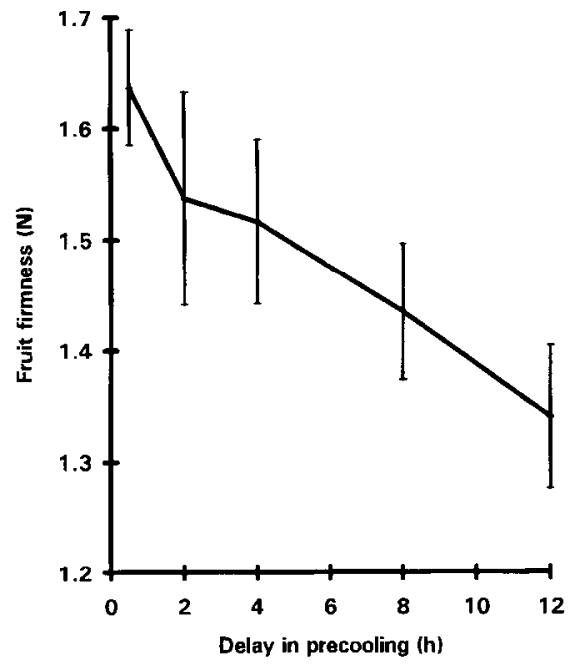

Fig. 2. The effect of delay before precooling on fruit strength of four cultivars of red raspberry fruit after storage in 1989. Vertical bars represent SE of the mean.
Table 2. Effect of delay in precooling on fruit strength during storage of Centennial red raspberry, 1990.

\begin{tabular}{|c|c|c|}
\hline \multirow{2}{*}{$\begin{array}{l}\text { Time of } \\
\text { measurement }\end{array}$} & \multicolumn{2}{|c|}{ elay before precooling ( $h$ ) } \\
\hline & 0.5 & 8 \\
\hline & \multicolumn{2}{|c|}{ Fruit strength $(N)$} \\
\hline After $0.5-h$ delay & $1.4 \mathrm{a}^{\mathrm{z}}$ & $1.6 \mathrm{a}$ \\
\hline After 8-h delay & - & $1.1 \mathrm{bc}$ \\
\hline After 4 -h precooling & $1.3 \mathrm{ab}$ & $1.2 \mathrm{~b}$ \\
\hline After 8 days stor- & & \\
\hline age at $0 \mathrm{C}$ & $1.1 \mathrm{~b}$ & $0.9 \mathrm{~d}$ \\
\hline After $24 \mathrm{~h}$ at $20 \mathrm{C}$ & $1.1 \mathrm{a}$ & $1.0 \mathrm{~cd}$ \\
\hline
\end{tabular}

less strength going into precooling and storage; this fruit continued to weaken during the S-day storage. Fruit strength did not change during the 24 $h$ at 20C, regardless of delay, and fruit strength was similar regardless of delay treatment.

Fruit color. In 1989, delaying precooling did not influence color of fruit stored for 8 days at $0 \mathrm{C}$ and measured after $24 \mathrm{~h}$ at 20C (data not shown). Any effect of delaying precooling may have been transient, and not apparent after 8 days at $0 \mathrm{C}$ and $24 \mathrm{~h}$ at $20 \mathrm{C}$. There were color differences among cultivars after the storage treatment, but all responded similarly to storage (data not shown). In 1990, color was measured on Centennial after precooling delays at $0.5,2,4,8$, or $12 \mathrm{~h}$ and a storage period of $0,2,4,6$, and 8 days. For Centennial, delay of precooling up through $4 \mathrm{~h}$ caused no color change. An 8-h delay before precooling resulted in significantly darker (lower L), less red (lower a), and more blue fruit (lower $b^{*}$ ) than fruit precooled after $0.5 \mathrm{~h}$ (data not shown). The 12-h delay further reduced $a^{*}$ and $b^{*}$ values. For Centennial in 1990, storage did not affect $L^{*}$ values, but $a^{*}$ and $b^{*}$ values had significant cubic effects (data not shown). This cultivar became more red and less blue over the 8 days of storage. This color change during storage has been observed by others ( $\mathrm{P}$. Bristow, unpublished data) and is a desirable trait in a cultivar used for fresh marketing.

\section{Summary}

This research indicated that delay of precooling resulted in greater weight loss during the delay period, which was somewhat compensated by a slower weight loss during subsequent precooling and cold storage. Even brief delays in precooling resulted in losses of fruit strength that continued during storage. Delay of precooling also resulted in darker, less red, and more blue fruit in a cultivar with high original color coordinate values. For long-distance fresh marketing raspberry fruit should be precooled as quickly as possible after harvest.

\section{Literature Cited}

Ingle, M. 1970. Studies on the post-harvest physiology and handling of strawberries. West Virginia Univ. Agr. Expt. Sta. Bul. 596T.

Kenny, A. 1975. Handling strawberries and raspberries for fresh market. 2. Precooling. Farm \& Food Res. 6:62-66.

Robbins, J.A. and T.M. Sjulin. 1986. A comparison of two methods for measurement of fruit strength in red raspberry. HortScience 21:1054-1055.

Robinson, J.E., K.M. Browne, and W.G. Burton. 1975. Storage characteristics of some vegetables and soft fruits. Ann. Applied Biol. 81:399-408.

Sjulin, T.M. and J.A. Robbins. 1987. Effects of maturity, harvest date, and storage time on postharvest quality of red raspberry fruit. J. Amer. Soc. Hort. Sci. 112:481487.

Salunkhe, D.K. and B.B. Desai. 1984. Small fruits-berries. Postharvest biotechnology of fruits. vol. I. CRC Press, Boca Raton, Fla.

Smith, W.H. 1958. The handling, precooling, transport and storage of strawberries and raspberries. Dept. of Scientific and Industrial Research, Food Investigation, Misc. Paper 1Q/58, London.

Tomalin, A. W., A. Farrimond, and D.T. Mason. 1972. Blueprint for long-distance transport of raspberries. The Grower, 15 July, p. 131-132.

\section{Acknowledgement}

H/LA Paper no. 90-33. Washington State Univ., College of Agriculture and Home Economics, Pullman. Project no. 0640. Partially supported by a grant from the Washington Red Raspberry Commission. We thank Terry s Berries for providing fruit. 